\title{
Multipoint targeting of the PI3K/mTOR pathway in mesothelioma
}

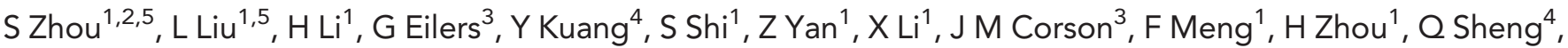 \\ J A Fletcher ${ }^{3}$ and W-B Ou ${ }^{*}, 1,3,4$ \\ ${ }^{1}$ Zhejiang Provincial Key Laboratory of Applied Enzymology, Department of Biotechnology and Biomedicine, Yangtze Delta \\ Region Institute of Tsinghua University, Jiaxing, China; ${ }^{2}$ Department of Bioengineering, College of Biology and Chemical \\ Engineering, Jiaxing University, Jiaxing, China; ${ }^{3}$ Department of Pathology, Brigham and Women's Hospital and Harvard Medical \\ School, Boston, MA, USA and ${ }^{4}$ Department of Biochemistry and Molecular Biology, College of Life Sciences, Zhejiang Sci-Tech \\ University, Hangzhou, China
}

Background: Mesothelioma is a notoriously chemotherapy-resistant neoplasm, as is evident in the dismal overall survival for patients with those of asbestos-associated disease. We previously demonstrated co-activation of multiple receptor tyrosine kinases (RTKs), including epidermal growth factor receptor (EGFR), MET, and AXL in mesothelioma cell lines, suggesting that these kinases could serve as novel therapeutic targets. Although clinical trials have not shown activity for EGFR inhibitors in mesothelioma, concurrent inhibition of various activated RTKs has pro-apoptotic and anti-proliferative effects in mesothelioma cell lines. Thus, we hypothesised that a coordinated network of multi-RTK activation contributes to mesothelioma tumorigenesis.

Methods: Activation of PI3K/AKT/mTOR, Raf/MAPK, and co-activation of RTKs were evaluated in mesotheliomas. Effects of RTK and downstream inhibitors/shRNAs were assessed by measuring mesothelioma cell viability/growth, apoptosis, activation of signalling intermediates, expression of cell-cycle checkpoints, and cell-cycle alterations.

Results: We demonstrate activation of the PI3K/AKT/P70S6K and RAF/MEK/MAPK pathways in mesothelioma, but not in non-neoplastic mesothelial cells. The AKT activation, but not MAPK activation, was dependent on coordinated activation of RTKs EGFR, MET, and AXL. In addition, PI3K/AKT/mTOR pathway inhibition recapitulated the anti-proliferative effects of concurrent inhibition of EGFR, MET, and AXL. Dual targeting of PI3K/mTOR by BEZ235 or a combination of RAD001 and AKT knockdown had a greater effect on mesothelioma proliferation and viability than inhibition of individual activated RTKs or downstream signalling intermediates. Inhibition of PI3K/AKT was also associated with MDM2-p53 cell-cycle regulation.

Conclusions: These findings show that PI3K/AKT/mTOR is a crucial survival pathway downstream of multiple activated RTKs in mesothelioma, underscoring that $\mathrm{PI} 3 \mathrm{~K} / \mathrm{mTOR}$ is a compelling target for therapeutic intervention.

Malignant mesothelioma is a locally aggressive and highly lethal neoplasm in which the neoplastic proliferation generally originates from pleural or peritoneal mesothelial cells (Craighead, 1987). An estimated 3000 cases per year are diagnosed in the United States, and most patients die within 1 year, with fewer than $5 \%$ of all patients cured even when intensive combined modality therapeutic strategies are employed. Mesothelioma has been linked to asbestos exposure (Craighead, 1987), and epidemiologic studies also show that mesothelioma risk increases after inhalation of the airborne mineral dust, erionite (Selcuk et al, 1992; Sahin et al, 1993). Mesothelioma histologic subtypes include epithelioid, spindled, or mixed (epithelioid and spindled; Craighead, 1987), of which the spindled subtype has the worst prognosis. Conventional chemotherapies and radiation therapy have only limited efficacy

*Correspondence: Dr W-B Ou; E-mail: ouwenbin@tsinghua.org.cn
${ }^{5}$ These authors contributed equally to this work.

Received 16 January 2014; revised 20 March 2014; accepted 27 March 2014; published online 24 April 2014

(c) 2014 Cancer Research UK. All rights reserved 0007 - 0920/14 
against mesothelioma, and improved survival will require development of novel and more effective pharmacological interventions. A better understanding of mesothelioma biology - including key growth factor signalling pathways - might be useful in identifying targets for novel therapeutics.

The increasing evidences suggest that receptor tyrosine kinase (RTK) activation participates in the oncogenic progression from non-neoplastic mesothelial progenitor cells to mesothelioma (Janne et al, 2002; Jagadeeswaran et al, 2006; Kawaguchi et al, 2009; Menges et al, 2010; Perrone et al, 2010; Brevet et al, 2011; Ou et al, 2011b). The RTKs epidermal growth factor receptor (EGFR), MET, AXL, and EPHB4, are upregulated and activated in some mesotheliomas (Janne et al, 2002; Xia et al, 2005; Jagadeeswaran et al, 2006; Ou et al, 2011a), resulting in downstream activation of the AKT/p70S6K and MAPK signalling pathways (Zanella et al, 1996; Pache et al, 1998). Nonetheless, HGF/MET activation has been convincingly implicated in mesothelioma pathogenesis, with this ligand/receptor pair co-ordinately overexpressed (Tolnay et al, 1998) and apparently contributing to invasiveness and proliferation (Klominek et al, 1998; Harvey et al, 2000). The MET inhibitor PHA-665752 exerts antiproliferative effects in mesothelioma cell lines by inhibiting MET-dependent PI3K/AKT and RAF/MAPK (Mukohara et al, 2005; Jagadeeswaran et al, 2006). AXL is expressed and activated strongly in mesothelioma cell lines and biopsies, and AXL inhibition by shRNA or a small molecule (DP-3975) suppresses mesothelioma migration and cellular proliferation, accompanied by inactivation of PI3K/AKT/mTOR and RAF/MAPK (Ou et al, 2011a). In addition, high AXL expression is associated with better prognosis in mesothelioma patients (Pinato et al, 2013). Activation of these receptors during asbestos-induced mesothelial mitogenicity and carcinogenesis thereby provides a promising connection between mesothelioma pathogenesis and potential drug targets. However, despite the evidence for tyrosine kinase activation in mesothelioma pathogenesis, targeted antikinase therapies have not shown dramatic clinical activity in mesothelioma patients. However, the observed activation of multiple RTKs in mesothelioma suggests that transforming activity is dependent on coordinated activity of multiple tyrosine kinases (Kawaguchi et al, 2009; Menges et al, 2010; Perrone et al, 2010; Brevet et al, 2011; Ou et al, 2011b), and simultaneous inhibition of multiple kinases by cocktails of small-molecule kinase inhibitors or single-agent HSP90 inhibitors elicits compelling pro-apoptotic and anti-proliferative responses in mesothelioma preclinical models (Okamoto et al, 2008; Kawaguchi et al, 2009; Ou et al, 2011b). In addition to the evidence for PI3K/AKT and RAF/MEK/MAPK activation in mesothelioma initiation, there is likewise substantial evidence that these key signalling pathways are crucial in maintaining the transformed state, and in mesothelioma metastasis (Altomare et al, 2005; Cole et al, 2006; Patel et al, 2007; Jacobson et al, 2009; Suzuki et al, 2009; Shukla et al, 2011; Carbone and Yang, 2012; Cedres et al, 2012; Fischer et al, 2012; Menges et al, 2012; Miyoshi et al, 2012; Pinton et al, 2012). In this study, we demonstrate PI3K/AKT/mTOR dependency on multiple activated RTKs in mesothelioma. We also demonstrate that dual targeting of the PI3K/AKT and mTOR is effective in blocking the proliferative and pro-survival signals from these activated RTKs.

\section{MATERIALS AND METHODS}

Antibodies and reagents. Monoclonal antibody to p53 and polyclonal antibodies to EGFR, MET, and AXL were from Santa Cruz Biotechnology (Santa Cruz, CA, USA). Monoclonal antibodies to AKT1 and S6, and polyclonal antibodies to AKT, AKT2, and AKT3 were from Cell Signaling Technology (Beverly, MA, USA). Antibodies to MAPK, MDM2, and p21 were from
Zymed/Invitrogen Laboratories (Invitrogen life Technologies, Carlsbad, CA, USA). All phospho-specific antibodies were from Cell Signaling Technology. Polybrene, puromycin, and antibody to $\beta$-actin were from Sigma-Aldrich (St Louis, MO, USA). Lentiviral shRNA constructs were from The RNAi Consortium (TRC, Cambridge, MA, USA), and included AXL: $5^{\prime}$-GCTGTGAAGACG ATGAAGATT-3'; AKT1: 5'-CGCGTGACCATGAACGAGTTT-3 ${ }^{\prime}$ (shRNA1), 5'-CGAGTTTGAGTACCTGAAGCT-3' (shRNA2), 5'-CTATGGCGCTGAGATTGTGTC- $3^{\prime}$ (shRNA3); and AKT2: 5'-CTTCGACTATCTCAAACTCCT-3' (shRNA1), 5' -CAAGGTA CTTCGATGATGAAT-3' (shRNA2); and AKT3: 5'-AGAAACCT CAAGATGTGGATT-3' (shRNA1), 5'-TGGCACACACTCTAAC TGAAA-3' (shRNA2).

Gefitinib, LY294002, U0126, GDC0941, and everolimus (RAD001) were obtained from LC Labs (Woburn, MA, USA). PHA-665752 was from Tocris Biosciences (St Louis, MO, USA). BEZ235 was from Axon MedchemBV (GZ Groningen, the Netherlands). All inhibitors were reconstituted in DMSO.

Mesothelioma cell lines. Mesothelioma cell lines MESO924, MESO257, and JMN1B were established in Dr Fletcher's laboratory from epithelial-type mesotheliomas (Demetri et al, 1989; Ou et al, 2011a), MESO296 was from a mixed histology mesothelioma, and MESO428 from a spindle-cell mesothelioma (Ou et al, 2011a,b). Each of these lines was previously shown to have survival and proliferation pathways dependent on activation of multiple RTKs (EGFR, MET, AXL). All cell lines were validated by demonstrating unique clonal cytogenetic aberrations within 10 passages of the present studies (MESO924, MESO257, MESO296, and MESO257 were validated by comparison with the corresponding surgical specimens, and JMN1B was validated by comparison with published cytogenetic aberrations). Normal mesothelial cells 97-510 were cultured in Dr Fletcher's laboratory from a nonneoplastic pleural effusion. Normal mesothelial cells HM3 were provided by Dr James Rheinhardt, having been established from non-neoplastic peritoneum, as described previously (Gordon et al, 2005).

Protein lysate preparations and immunoblotting. Signalling pathway phosphorylation analyses were performed by immunoblotting mesothelioma cell lysates after $4 \mathrm{~h}$ treatment with various inhibitors in serum-free medium, and after 4 or 10 days post infection with kinase shRNAs. Whole-cell lysates were prepared using lysis buffer (1\% NP-40, $50 \mathrm{~mm}$ Tris- $\mathrm{HCl}$ pH 8.0, $100 \mathrm{~mm}$ sodium fluoride, $30 \mathrm{~mm}$ sodium pyrophosphate, $2 \mathrm{~mm}$ sodium molybdate, $5 \mathrm{~mm}$ EDTA, and $2 \mathrm{~mm}$ sodium orthovanadate) containing protease inhibitors $\left(10 \mu \mathrm{g} \mathrm{ml}^{-1}\right.$ aprotinin, $10 \mu \mathrm{g} \mathrm{ml}^{-1}$ leupeptin, and $1 \mathrm{~mm}$ phenylmethylsulfonyl fluoride). Lysates were cleared by centrifugation at 14000 r.p.m. for $30 \mathrm{~min}$ at $4{ }^{\circ} \mathrm{C}$, and lysate protein concentrations were determined using a Bio-Rad protein assay (Bio-Rad Laboratories, Hercules, CA, USA). Electrophoresis and western blotting were performed as described previously (Rubin et al, 2001). The hybridisation signals were detected by chemiluminescence (Immobilon Western, Millipore Corporation, Billerica, MA, USA) and captured using a GE FUJI ImageQuant LAS4000 chemiluminescence imaging system (GE Healthcare Bio-Sciences Corporation, Piscataway, NJ, USA). Intensity of phospho-AKT signal was quantitated by an Image analyzer, FUJIFILM MultiGauge (Fuji Film, Tokyo, Japan).

Preparation of shRNA lentiviruses. Lentivirus preparations were produced by cotransfecting empty vector pLKO.1puro with $A X L$, $A K T 1, A K T 2$, or $A K T 3$ shRNAs, and helper virus packaging plasmids pCMV $\delta$ R8.91 and pMD.G (at a 10:10:1 ratio) into 293T cells. Transfections were carried out using lipofectamine and PLUS reagent (Invitrogen Life Technologies). Lentiviruses were harvested at $24,36,48$, and $60 \mathrm{~h}$ post transfection. Virus was frozen at 
$-80{ }^{\circ} \mathrm{C}$ in appropriately sized aliquots for infection. shRNAs were used for AXL, AKT1, AKT2, and AKT3 knockdowns.

Cell culture and virus infection. Mesothelioma cell lines were cultured in RPMI 1640 medium supplemented with 10\% fetal bovine serum and seeded in six-well plates. Lentiviral shRNA infections were carried out in the presence of $8 \mu \mathrm{g} \mathrm{ml}^{-1}$ polybrene. Following transduction, MESO924 and MESO428 cells were selected for stable expression of the AKT1 or AKT2 shRNAs using $2 \mu \mathrm{g} \mathrm{ml}^{-1}$ puromycin. Cells were lysed for western blotting or viability analysis 10 days post infection. Mesothelioma cell lines were lysed for western blotting 4 days post infection with AKT3 shRNAs.

Cell proliferation and apoptosis assays. Mesothelioma cells including MESO924, MESO257, MESO296, and MESO428, and normal mesothelial cells 97-510 were plated at 3000 and 10000 cells per well, respectively, in a 96-well flat-bottomed plate (Falcon, Lincoln, NJ, USA) and cultured in media for $24 \mathrm{~h}$ before being treated with different inhibitors, which included gefitinib $(1 \mu \mathrm{M})$, PHA665752 $(1 \mu \mathrm{M}), \operatorname{BEZ235}(10,25,50,100,500$, and $1000 \mathrm{~nm})$, GDC0941 $(0.5,1,2.5,5$, and $10 \mu \mathrm{M})$, RAD001 (20 nM), and U0126 $(10 \mu \mathrm{M})$, or AXL shRNA. MESO924 and MESO428 cells with AKT1 and AKT2 shRNA stable expression (selection by puromycin for 10 days after infection) were plated at 3000 cells per well in a 96-well flat-bottomed plate and cultured for $24 \mathrm{~h}$ before being treated with BEZ235 (50 nM), RAD001 (20 nM), and U0126 (10 $\mu \mathrm{M})$. Cell viability was determined after treatment with these inhibitors for 3 and 6 days using the CellTiter-Glo luminescent assay (Promega, Madison, WI, USA), and measured using a Veritas Microplate Luminometer (Turner Biosystems, Sunnyvale, CA, USA). The data were normalised to the control group (empty vector or DMSO). The chemosensitivity assay by sulforhodamine B (SRB) was performed after $72 \mathrm{~h}$, following a slightly modified protocol (Skehan et al, 1990). Briefly, the cells in 96-well plates were fixed in $30 \%$ trichloracetic acid ( $50 \mu \mathrm{l}$ per well) for $1 \mathrm{~h}$ at $4{ }^{\circ} \mathrm{C}$, rinsed in tap water for five times and stained with $0.4 \%(\mathrm{w} / \mathrm{v})$ SRB in $1 \%$ acetic acid ( $70 \mu \mathrm{l}$ per well) for $30 \mathrm{~min}$ at room temperature. The cells were then rinsed four times in $1 \%$ acetic acid to remove the unbound stain. The protein-bound stain was extracted with $100 \mu \mathrm{l}$ $10 \mathrm{~mm}$ Tris base ( $\mathrm{pH} 10.5$ ) per well. The optical density was read at $540 \mathrm{~nm}$ in a SpectraMax M5 Micro plate Reader (Molecular Devices, Sunnyvale, CA, USA). The results were expressed as cell growth determined according to the following equation: cell growth $=\left(A_{\text {treated sample, } 72 \mathrm{~h}}-A_{\text {untreated control, } 0 \mathrm{~h}}\right)$, where $A$ is absorbance. The $\mathrm{IC}_{50}$ values were defined as the concentration that causes $50 \%$ growth inhibition. IC $_{50}$ values were calculated using a sigmoidal curve fit with GraphPad Prism software (GraphPad Software, Inc., La Jolla, CA, USA). All experimental points were setup in four replicate wells and independently performed in duplicate.

Apoptosis was also evaluated using PE Annexin V Apoptosis Detection Kit I (BD Pharmingen, San Jose, CA, USA). Briefly, MESO924, MESO257, MESO296, and MESO428 cells in six-well plates were treated with BEZ235 (50 nM) or LY294002 (10 $\mu \mathrm{M})$ for $48 \mathrm{~h}$, trypsinised and washed twice with cold Hanks Balanced Salt Solution and treated with $5 \mu \mathrm{l}$ of PE Annexin V and $5 \mu \mathrm{l}$ 7-AAD in $1 \times$ Binding Buffer for $15 \mathrm{~min}$ at RT $\left(25^{\circ} \mathrm{C}\right)$ in dark. The stained cells were analysed in a flow cytometer within $1 \mathrm{~h}$ and ModFit LT (Macitosh, Verity Software House, Topsham, ME, USA) was used to analyse the data.

Cell cycle analysis. MESO924, MESO257, MESO296, and MESO428 cells in six-well plates were treated with inhibitors for $48 \mathrm{~h}$, then trypsinised, and washed once with Hanks Balanced Salt Solution. For nuclear staining, cells were fixed by $70 \%$ ethanol for $24 \mathrm{~h}$. A propidium iodide-containing solution (Roche, South San Francisco, CA, USA) was added to the cells and incubated for
$15 \mathrm{~min}$ at $37^{\circ} \mathrm{C}$. The cell suspension was analysed on a flow cytometer within $48 \mathrm{~h}$ and ModFit LT (Macintosh) was used to fit the data. Cell-cycle analysis was independently performed in duplicate.

Statistical analysis. Student's $t$-tests or one-way ANOVA was performed to analyse data from cells treated with control DMSO or inhibitors, as well as cells treated with control DMSO, pLKO, combination of gefitinib, PHA, and AXL shRNA, or combination of RAD and AKT1 shRNA/AKT2 shRNA. Statistically significant differences between untreated control and treatment are defined as ${ }^{\star} P<0.05,{ }^{* *} P<0.01$, and ${ }^{\star * *} P<0.001$.

\section{RESULTS}

Activation of AKT, S6, and MAPK. Using normal mesothelial cells (97-510 and HM3) as a reference point, AKT and S6 were activated strongly in each of five mesothelioma cell lines (MESO924, MESO257, MESO296, MESO428, and JMN1B) and MAPK (MAPK1/3) was activated in each line except JMN1B (Figure 1).

Biologic effects of PI3K/mTOR, PI3K, mTOR, and MEK inhibition in mesothelioma cell lines. PI3K inhibition by BEZ235 (10 and 50 nM), GDC0941 (500 and $1000 \mathrm{~nm}$ ), and LY294002 (10 and $50 \mu \mathrm{M}$ ) substantially inhibited AKT in all mesothelioma cell lines (Figure 2A). mTOR inhibition by the rapamycin derivative RAD001/everolimus or by BEZ235 abolished S6 phosphorylation, whereas selective PI3K inhibition with GDC0941 only partially inhibited S6 (Figure 2A). LY294002 inhibited AKT effectively, but had unpredictable effects on S6, confirming the nonselective activity of this broadly active PI3Kfamily inhibitor. MEK1/2 inhibition by $10 \mu \mathrm{M}$ U0126 inhibited MAPK, as expected, in all mesothelioma cell lines but had little impact on S6 phosphorylation (Figure 2A).

The biological relevance of PI3K, mTOR, and MEK was evaluated by determining impact on cell proliferation (Figure 2B). Dual targeting of PI3K/mTOR with BEZ235 (50 nM) inhibited cell proliferation by $74 \%, 78 \%, 64 \%$, and $60 \%$ in MESO924, MESO257, MESO296, and MESO428, respectively

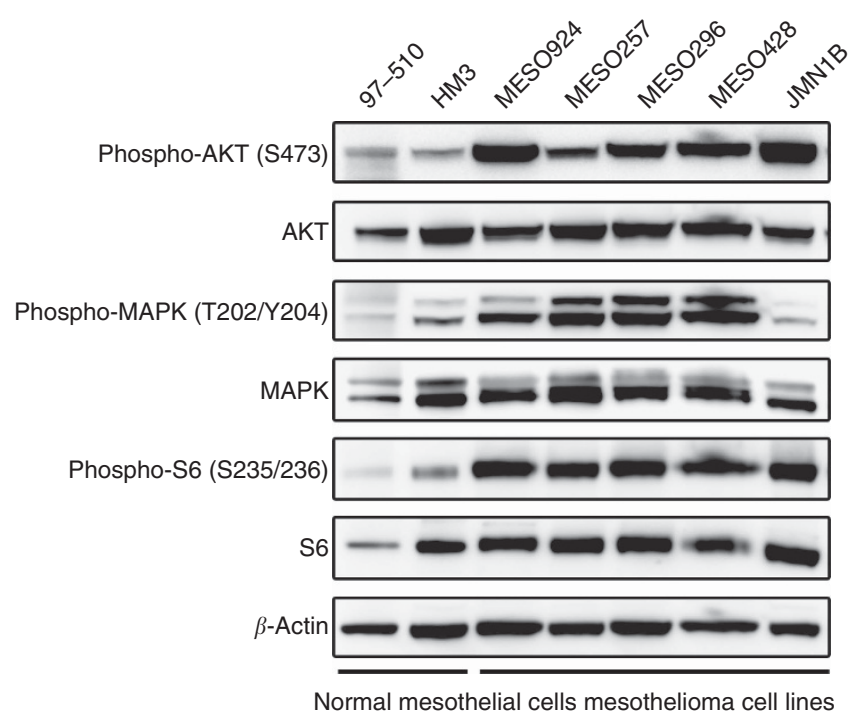

Figure 1. Immunoblotting evaluation of expression and phosphorylation of signalling intermediates including AKT, MAPK, and S6 in mesothelioma cell lysates. Non-neoplastic mesothelial cells (97-510 and HM3) are controls for comparison. $\beta$-Actin staining is a loading control. 

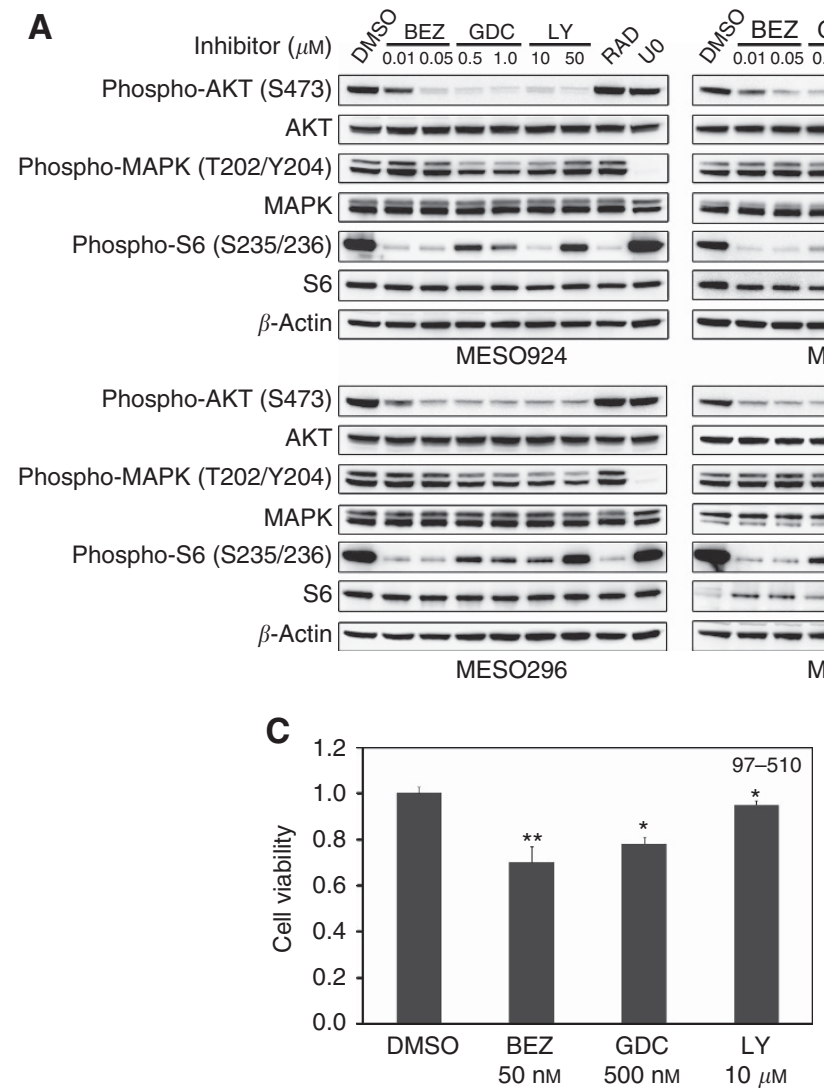

B

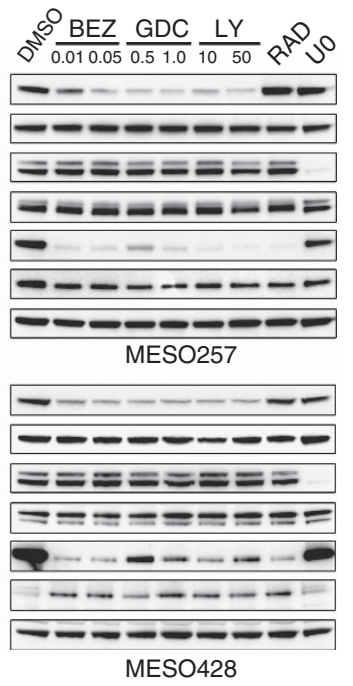

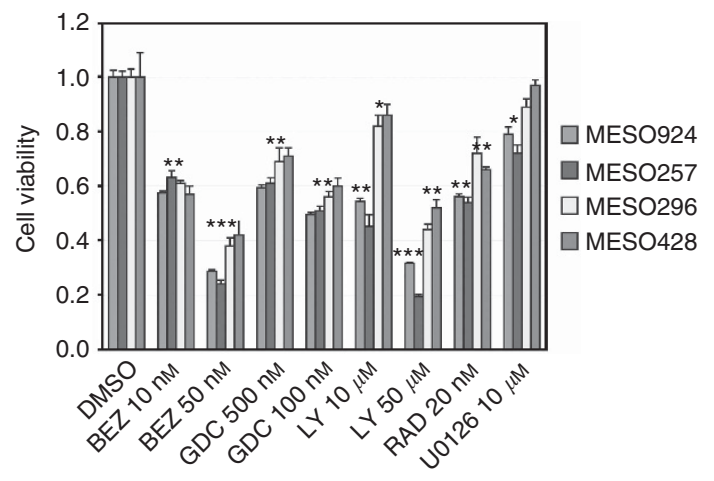

D MESO 924 and 428 SRB assay

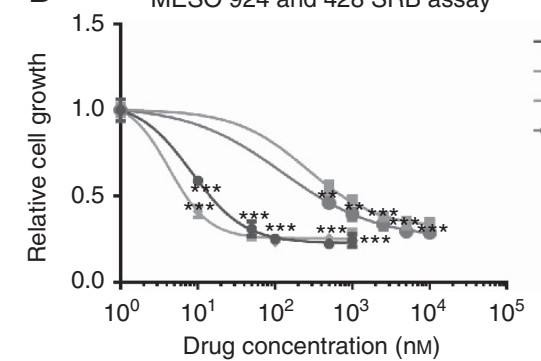

-MESO924 BEZ
-MESO924 GDC
- MESO428 BEZ

MESO428 GDC

Figure 2. (A) Effects of inhibitors of PI3K/mTOR (BEZ235), PI3K (GDC0941 and LY294002), mTOR (RAD001, 20 nM), and MEK (U0126, $10 \mu M)$ on AKT, MAPK, and S6 activation in mesothelioma total cell lysates, after $4 \mathrm{~h}$ treatment in serum-free media. $\beta$-Actin stain is a loading control. (B) Mesothelioma cell and (C) non-neoplastic mesothelial cells (97-510) viability after $72 \mathrm{~h}$ treatment with inhibitors including BEZ235 (PI3K/mTOR), GDC0941 and LY294002 (PI3K), RAD001 (mTOR), and U0126 (MEK), using the CellTiter-Glo assay. Data were normalised to the DMSO control, and represent the mean values ( \pm s.d.) of quadruplicate cultures from two independent experiments. (D) The inhibition of cell growth in mesothelioma lines (MESO924 and MESO428) after $72 \mathrm{~h}$ treatment with BEZ235 (10, 50, 100, 500, and 1000 nM) and GDC0941 (0.5, 1, 2.5, 5, and $10 \mu \mathrm{M})$, RAD001 (mTOR), and U0126 (MEK) was evaluated by using the SRB assay. Data are shown as the difference between absorbance of control cells at $72 \mathrm{~h}$ vs time zero, and represent the mean values ( \pm s.d.) of quadruplicate cultures from two independent experiments. Statistically significant difference of Student's $t$-test between untreated control and treatments is presented as ${ }^{\star} P<0.05,{ }^{\star \star} P<0.01,{ }^{\star \star \star} P<0.001$.

(Figure 2B). Selective PI3K inhibition by GDC0941 resulted in $40-50 \%$ inhibition of these mesothelioma cells, and broader PI3K family inhibition with LY294002 markedly decreased cell proliferation in all mesothelioma cell lines (Figure 2B). Selective mTOR inhibition by RAD001 was associated with moderate antiproliferative effects (30-40\% reduction in proliferation), and MEK inhibition by U0126 had only minor effects (5-25\% reduction in proliferation) in all mesothelioma cell lines (Figure 2B). Indeed, the antiproliferative effects of PI3K/mTOR inhibition by BEZ235 were substantially greater than those induced by GDC0941, RAD001, and U0126 treatment alone in all mesothelioma cell lines (Figure 2B). By contrast, PI3K inhibition by BEZ235, GDC0941, and LY294002 had only mild anti-proliferative effects in normal mesothelial cells 97-510 (Figure 2C). Furthermore, cell growth, as assessed using the SRB assay, was strongly inhibited in MESO924 and MESO428 cell lines after PI3K/mTOR inhibition by BEZ235 or PI3K inhibition by GDC0941 (Figure 2D). Cell growth inhibition $\mathrm{IC}_{50}$ s at day 3 were 14 and $744 \mathrm{~nm}$ for MESO924, and 7 and $356 \mathrm{~nm}$ for MESO428, respectively (Figure 2D), suggesting that BEZ235 has more potent anti-proliferative effects in mesotheliomas than GDC0941.

Multiple activated RTKs in individual mesothelioma cells contribute collectively to PI3K/AKT activation. The impact of single or combination tyrosine kinase inhibitor treatments on the phosphorylation of AKT and MAPK was determined in MESO924 and MESO428 (Figure 3A). EGFR, MET, and AXL inhibition by $1 \mu \mathrm{M}$ gefitinib, $1 \mu \mathrm{M}$ PHA665752, and AXL shRNA substantially inhibited EGFR, MET, and AXL phosphorylation, respectively, in these cell lines. Maximal reduction of AKT phosphorylation (69\% reduction in MESO924 and 61\% in MESO428) was achieved by coordinated inhibition of EGFR, MET, and AXL, compared with DMSO and empty vector treatment controls. EGFR and AXL inhibition, singly or in combination, had a moderate effect on AKT and S6 phosphorylation. Combination inhibition of MET and AXL resulted in $29 \%$ and $57 \%$ decrease in AKT phosphorylation in MESO924 and MESO428, respectively, whereas MET inhibition alone resulted in 19 and 10\% decrease in AKT phosphorylation. EGFR, MET, and AXL inhibition, singly or in combination, had little effect on MAPK and S6 activation (Figure 3A).

We next compared effects of the PI3K/mTOR inhibitor BEZ235 on cell viability, compared with those obtained by direct targeting of EGFR, MET, and AXL. As shown in Figure 3B, the most striking reduction in cell viability was seen in cells treated with BEZ235 or with concurrent direct targeting of EGFR, MET, and AXL; these approaches resulted in $\sim 70 \%$ and $\sim 60 \%$ decrease in cell viability, respectively. EGFR and MET targeting had little effect on cell viability, whereas AXL targeting resulted in $\sim 50 \%$ reduction of mesothelioma viability (Figure 3B).

As AKT activation but not MAPK is dependent on coordinate activation of EGFR, MET, and AXL, we investigated whether combination inhibition of PI3K and MAPK has additive or 
A

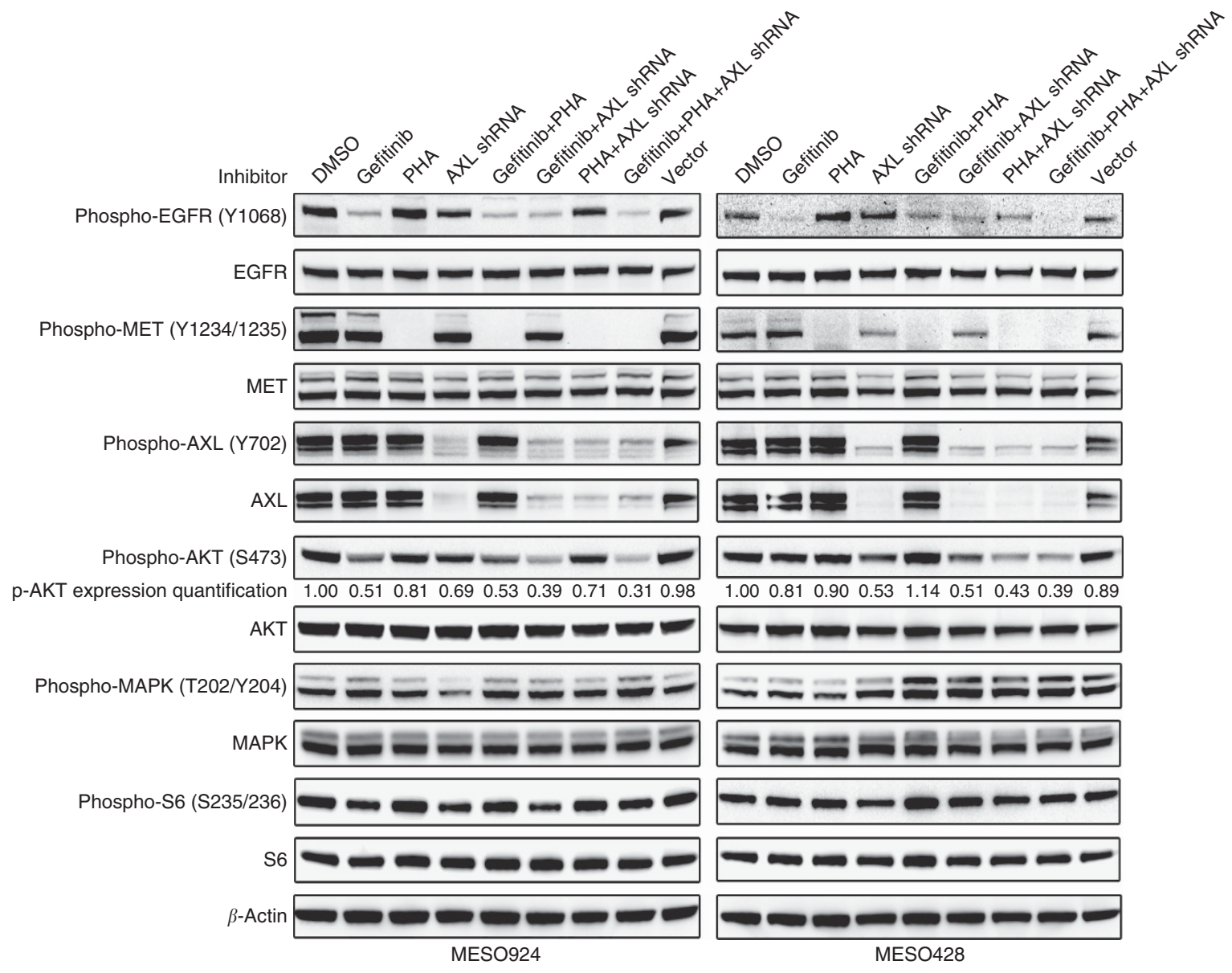

B

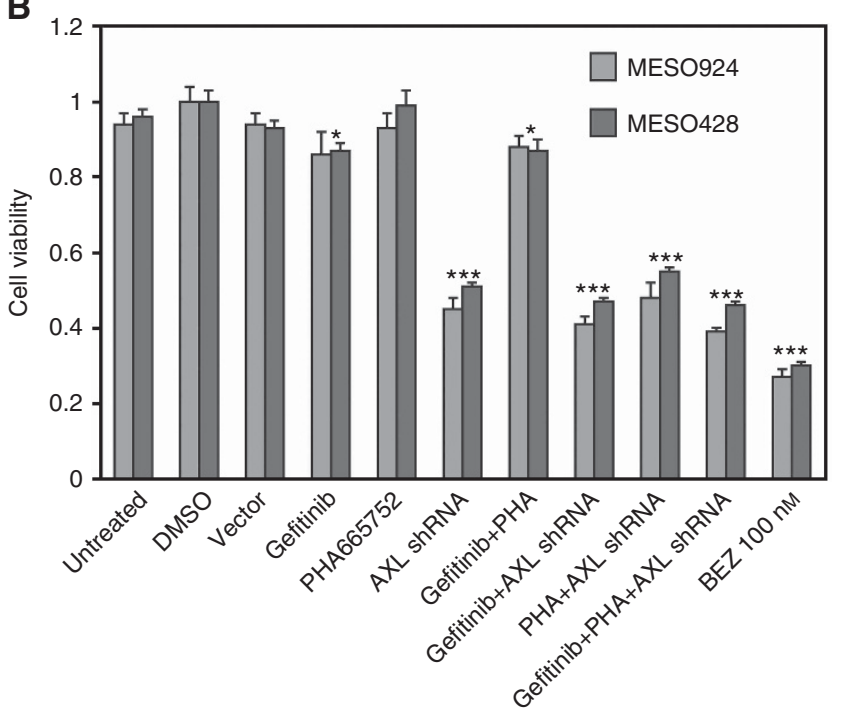

C

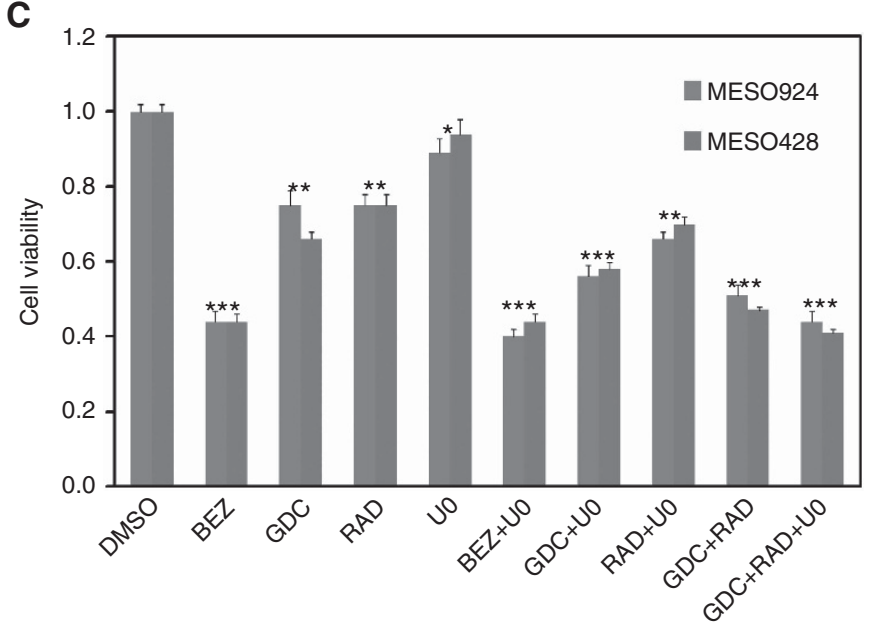

Figure 3. Single vs combination tyrosine kinase inhibitor treatments on mesothelioma. (A) Immunoblotting evaluations of inactivation of multiple RTKs (EGFR, MET, and AXL) and signalling intermediates (AKT, MAPK, and S6) in mesothelioma cell lines (MESO924 and MESO428) after $4 \mathrm{~h}$ treatment in serum-free media with EGFR (1 $\mu \mathrm{M}$ gefitinib), MET (1 $\mu \mathrm{M}$ PHA665752) inhibitor, or post-infection with AXL shRNA at $72 \mathrm{~h}$ alone and combined. $\beta$-Actin stain is a loading control. phospho-AKT expression quantification is normalised to DMSO treatment control. (B) Cell viability, in mesothelioma cell lines MESO924 and MESO428, was evaluated by the CellTiter-Glo luminescence assay after $72 \mathrm{~h}$ treatment with EGFR (1 $\mu \mathrm{M}$ gefitinib), MET (1 $\mu \mathrm{M}$ PHA665752), or AXL (AXL shRNA) inhibitor alone and together, PI3K/mTOR inhibitor (100 nM BEZ235). The data were normalised to the DMSO control, and represent the mean values ( \pm s.d.) of quadruplicate cultures. (C) Cell viability, in MESO924 and MESO428, was evaluated by the CellTiter-Glo luminescence assay after $72 \mathrm{~h}$ treatment with BEZ235 (50 nM), GDC0941 (0.5 $\mu \mathrm{M}), \mathrm{RAD} 001$ (20 nM), or U0126 $(10 \mu \mathrm{M})$ alone and together. The data were normalised to the DMSO control, and represent the mean values ( \pm s.d.) of quadruplicate cultures from two independent experiments. Statistically significant difference of one-way ANOVA between untreated control and treatments is presented as $\star P<0.05,{ }^{\star} * P<0.01, * \star \star P<0.001$. 
synergistic anti-proliferative effects in mesothelioma. Cell viability was strongly inhibited in MESO924 and MESO428 after $\mathrm{PI} 3 \mathrm{~K} / \mathrm{mTOR}$ inhibition by BEZ235 or GDC0941/RAD (Figure 3C). The additive inhibitory effects were seen after treatment with GDC0941/U0126 targeting PI3K and MAPK, RAD/U0126 targeting mTOR and MAPK, or GDC0941/RAD targeting PI3K and mTOR. The anti-proliferative effects of combination inhibition of PI3K/mTOR and MAPK by BEZ235/U0126 or GDC0941/RAD/ U0126 were comparable with inhibition of $\mathrm{PI} 3 \mathrm{~K} / \mathrm{mTOR}$ (Figure $3 \mathrm{C}$ ), indicating that $\mathrm{PI} 3 \mathrm{~K} / \mathrm{mTOR}$ signalling has a crucial oncogenic role in mesothelioma.

$\mathrm{PI} 3 \mathrm{~K} / \mathrm{mTOR}$ is a crucial regulator of mesothelioma viability and survival. Cell viability, as assessed using an ATP-based assay (CellTiter-Glo), was strongly inhibited in all mesothelioma cell lines after PI3K/mTOR inhibition by BEZ235 (Figure 4A). Cell proliferation $\mathrm{IC}_{50} \mathrm{~s}$ at day 3 were $11.8 \mathrm{~nm}$ for MESO924, $11.4 \mathrm{~nm}$ for MESO257, $12 \mathrm{~nm}$ for MESO296, and $10.8 \mathrm{~nm}$ for MESO428, suggesting that BEZ235 has potent anti-proliferative effects in mesotheliomas with either spindle-cell components (MESO296 and MESO428) or in those with purely epithelial-type histology (MESO924 and MESO257).

Cell-cycle analyses demonstrated a dose-dependent G1 block with decrease in the S-phase population after selective PI3K inhibition by GDC0941 in each of four mesothelioma lines, and after PI3K/mTOR inhibition by BEZ235 in those with epithelialtype histology (MESO924 and MESO257) (Figure 4B). Mild apoptosis after PI3K/mTOR inhibition was observed by nuclear fragmentation in mesothelioma with spindle-cell components (MESO296 and MESO428; pre-G1 peak). Fragmented-apoptotic cells, in MESO296 and MESO428 treated with DMSO-only control and $50 \mathrm{nM}$ BEZ235, were $9 \%$ and $18 \%$, respectively, in MESO296; and $12 \%$ and $20 \%$, respectively, in MESO428 (Figure 4B). Nuclear fragmentation after selective PI3-K inhibition with GDC0941 did not substantially exceed levels seen in control arms in which the cells were exposed to DMSO alone (Figure 4B). In MESO296 and MESO428, mild apoptosis was induced by treatment with BEZ235 and LY294002 (Supplementary Figure 1), which is consistent with the cell-cycle analysis (Figure 4B). Immunoblotting did not show expression of cleaved PARP, cleaved caspase 3, or cleaved caspase 8 after treatment with BEZ235 or GDC0941 (data not shown), indicating that PI3K inhibition in these cells mostly results in inhibition of cell growth, not apoptosis.

Dual targeting of PI3K/mTOR signalling by BEZ235 was evaluated by immunoblotting (Supplementary Figure 2), proliferation, and cell-cycle analyses (Figure 4). AKT and S6 were substantially inactivated in all four mesothelioma cell lines in a dose-dependent manner (MESO924, MESO257, MESO296, and MESO428) after PI3K/mTOR inhibition, and S6 phosphorylation was almost completely lost after $10 \mathrm{nM}$ BEZ treatment (Supplementary Figure 2).

PI3K/AKT regulates $\mathrm{p} 53$ via MDM2 activity in mesothelioma. AKT inhibition by GDC0941 abolished MDM2 phosphorylation at Ser166 and induced p53 and p21 expression (Figure 5A). AKT1 and AKT2 gene expression were stably silenced by lentiviral shRNA infections with puromycin selection. AKT1 and AKT2 knockdown by $\operatorname{sh} R A$, whether singly or in combination, induced expression of p53, MDM2, and p21 (Figure 5B), consistent with AKT-mediated MDM2 functional inactivation, with resultant p53 overexpression and transcriptional activation of MDM2 and p21. The AKT1 and AKT2 knockdowns resulted in $\sim 40 \%$ inhibition of cell viability (CellTiter-Glo assay), at 3 and 6 days after AKT1 or AKT2 silencing, compared with the empty vector control (Figure 5C). The most striking reductions in cell viability $(60 \%$ and $80 \%$, at days 3 and 6 , respectively) were seen after combined $\mathrm{PI} 3 \mathrm{~K} / \mathrm{mTOR}$ inhibition (with BEZ235) or after mTOR inhibition (with RAD001) combined with shRNA knockdown of AKT1 or
AKT2 (Figure 5C). By contrast, MEK inhibition had substantially less impact on mesothelioma viability (Figure 5C). All lentiviral shRNA studies were confirmed using at least two independent shRNA transductions and using at least one additional AKT1 and AKT2 shRNA sequence (Supplementary Figure 3). Moreover, AKT1 and AKT2 inhibition by shRNA, whether singly or in combination, resulted in increases of mTORC1 substrate p-S6 (Supplementary Figure 4). In addition, AKT3 knockdown by shRNA also induced expression of p53, MDM2, p21, and p-S6 (Supplementary Figure 5).

\section{DISCUSSION}

Despite the use of aggressive multimodal therapy, mesothelioma remains a highly lethal disease, and an unmet medical need, underscoring the need for additional biologic insights as preclinical validations for targeted therapies. We previously reported that multiple RTKs, including EGFR, MET, and AXL, are co-activated in an HSP90-dependent manner in mesothelioma but not in nonneoplastic mesothelial cells ( $\mathrm{Ou}$ et al, 2011b), and those findings are corroborated in the present study (Figure 3A). Because targeting of individual RTKs has shown little clinical benefit (Govindan et al, 2005; Mathy et al, 2005), we hypothesise that simultaneous inhibition of multiple RTKs, or their consensus oncogenic pathways, is required for substantial clinical activity. In this light, the studies reported herein add to the already substantial evidence that targeting the crucial PI3K/mTOR pathway might be an effective strategy in mesothelioma, specifically by inhibiting oncogenic signals from the multiple activated RTKs.

Previously, several studies have shown elevated AKT activity in mesothelioma (Altomare et al, 2005; Suzuki et al, 2009; Pinton et al, 2012). Our findings confirm aberrant activation of $\mathrm{PI} 3 \mathrm{~K} / \mathrm{AKT} / \mathrm{mTOR}$ and RAF/MEK/MAPK in mesothelioma cells, as compared with non-neoplastic mesothelial cells (Figure 1). Inhibition of PI3K, mTOR and MEK decreased cell viability in all mesothelioma lines by inducing cell apoptosis and G1/G2 cell-cycle arrest (Figures 2B and D, 4A and B and Supplementary Figure 1). Indeed, each of these 'downstream' targeting approaches had greater impact on mesothelioma viability than was observed after EGFR, MET, or AXL inhibition (Figures $3 \mathrm{~B}$ and $5 \mathrm{C}$ ). The antiproliferative effects of combination inhibition of PI3K/mTOR and MAPK were comparable with inhibition of PI3K/mTOR (Figure 3C). Notably, maximal mesothelioma inhibition resulted from inhibition of the PI3K/AKT/mTOR pathway, in which PI3K and mTOR were biochemically inhibited by the small-molecule dual PI3K and mTOR inhibitor, BEZ235, and AKT1 and AKT2 were inhibited by shRNA-mediated knockdown. With this approach, $70-80 \%$ reduction in viability/cell growth was seen in each mesothelioma line (Figures $2 \mathrm{~B}$ and D). Although smallmolecule AKT inhibitors were not evaluated in these studies, our findings suggest that therapeutic benefit might result from concurrent targeting of multiple nodes in key pathways. Such approaches could potentially minimise treatment resistance due to feedback loops such as the well-documented compensatory upregulation of AKT activity that is often induced by mTOR inhibition (Rodrik-Outmezguine et al, 2011). Approaches in which a crucial pathway is targeted at multiple points might also permit effective targeting of the pathway at lower concentrations of each individual drug, and therefore with reduced toxicity to the patient.

In the present study, the treatment of mesothelioma cell lines with the dual PI3K/mTOR inhibitor BEZ235 or mTOR inhibitor RAD001 did not result in upregulation of the MAPK signalling pathway (Figure 2A), which is in contrast to other experimental models in which RAD001 induced activation of MEK/MAPK signalling because of activation of p70S6K-PI3K-signalling 


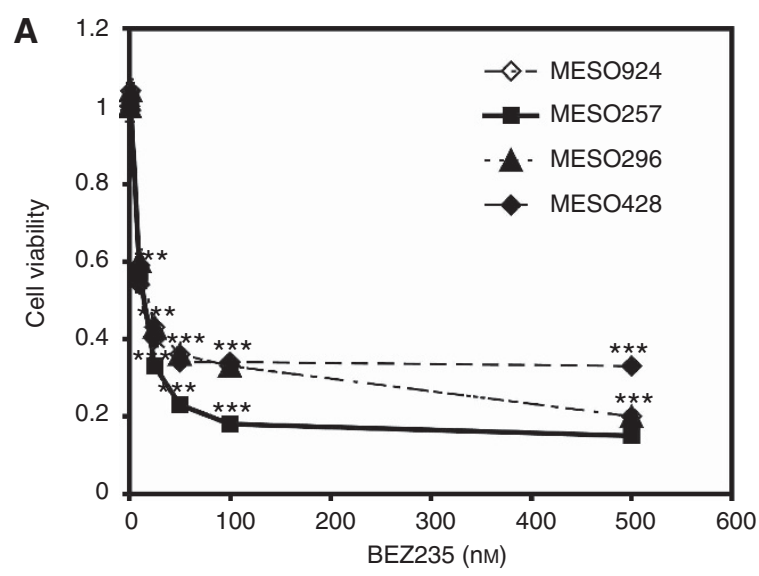

B

DMSO
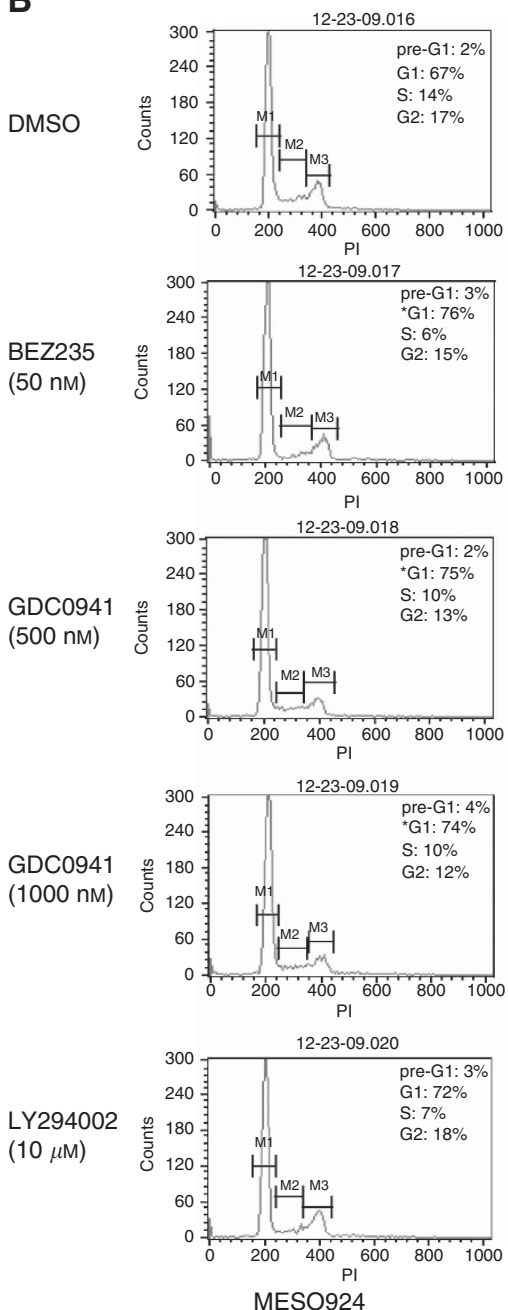

MESO924
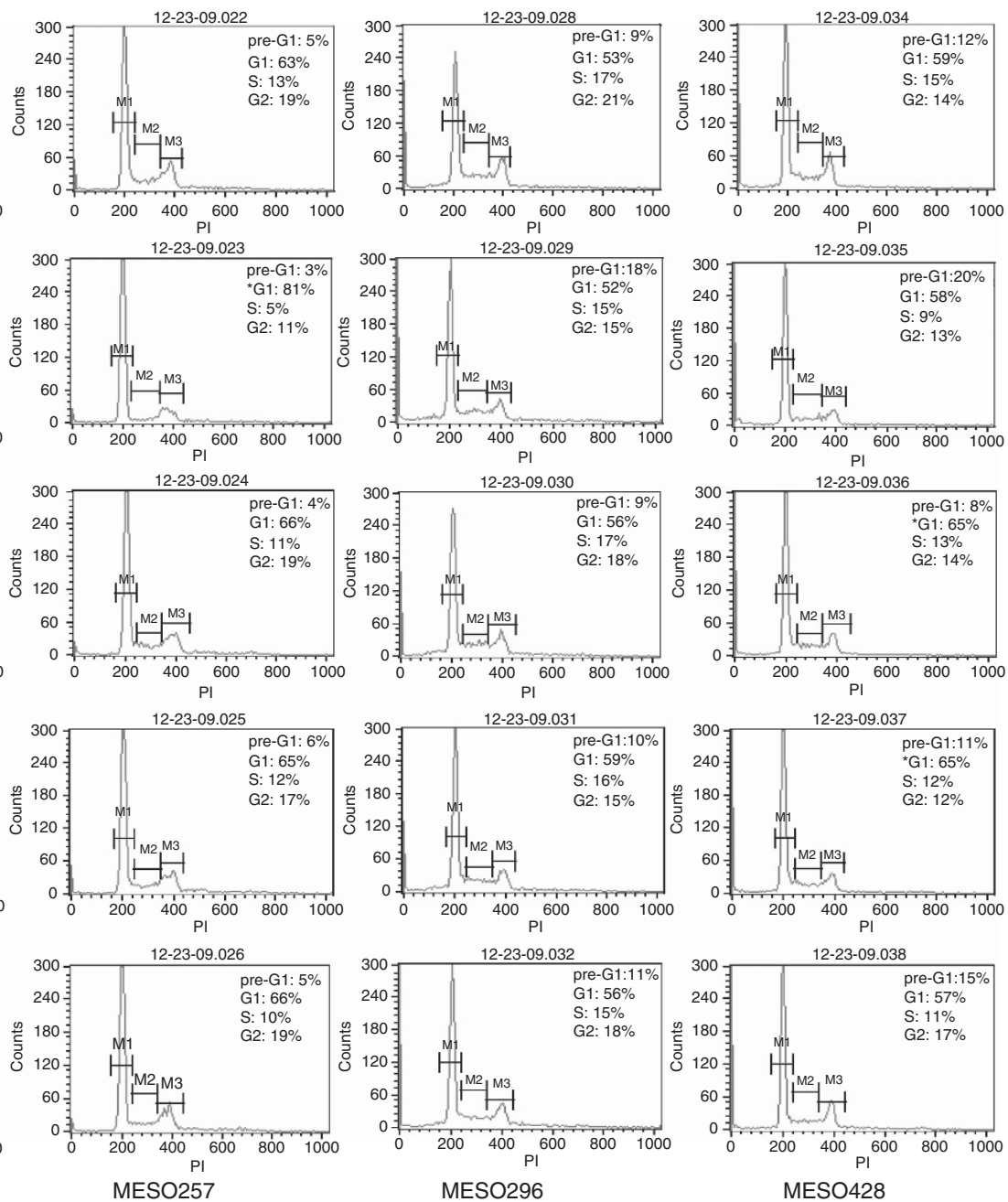

Figure 4. $\mathrm{PI} 3 \mathrm{~K} / \mathrm{mTOR}$ signalling regulation of mesothelioma proliferation and survival. (A) Mesothelioma cell viability after $72 \mathrm{~h}$ treatment with $\mathrm{PI} 3 \mathrm{~K} / \mathrm{mTOR}$ inhibitor, BEZ235, using the CellTiter-Glo assay. The data are normalised to the DMSO control, and represent the mean values ( \pm s.d.) of quadruplicate cultures from two independent experiments. Statistically significant difference between untreated control and treatments is presented as ${ }^{*} P<0.05,{ }^{\star \star} P<0.01,{ }^{\star \star \star} P<0.001$. (B) Cell-cycle analyses after BEZ235, GDC0941, or LY294002 treatment for $48 \mathrm{~h}$ in serumcontaining medium. Cell-cycle analysis was independently performed in duplicate. Statistical analysis was performed comparing the apoptosis induction or G1 arrest of the inhibitor treatment and DMSO-treated cells with t-test. ${ }^{\star} P<0.05$.

(Carracedo et al, 2008). Although the mechanism is unclear, herein, inhibition of mTOR by RAD001 little increased PI3K/AKT signalling in mesothelioma cell lines (Figure 2A), which can interpret this contradiction. This was also demonstrated by the comparable anti-proliferative effects of either mTOR inhibition alone or in combination with MAPK inhibition in mesothelioma cell lines (Figure 3C).
As mentioned above, therapeutic modalities directed at individual RTKs have not shown dramatic preclinical or clinical activity in mesothelioma (Figure 3). In the present study, substantial inhibition of AKT phosphorylation was achieved by coordinated inhibition of EGFR, MET, and AXL (Figure 3A). These findings indicate that multiple RTKs contribute to PI3K/ AKT oncogenic signalling in mesothelioma. Combined 
A

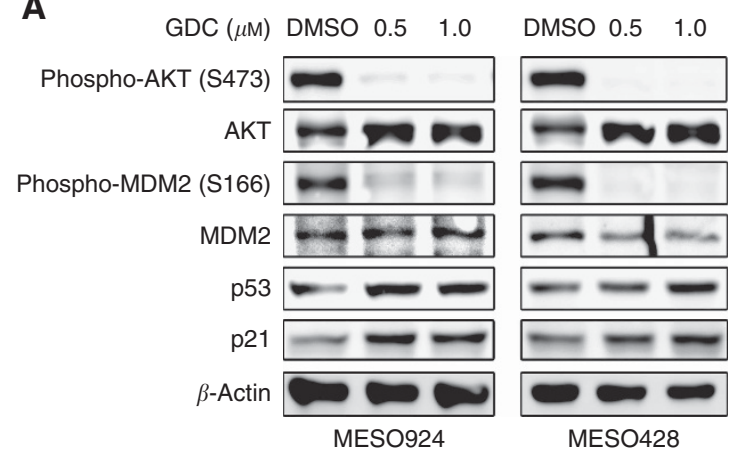

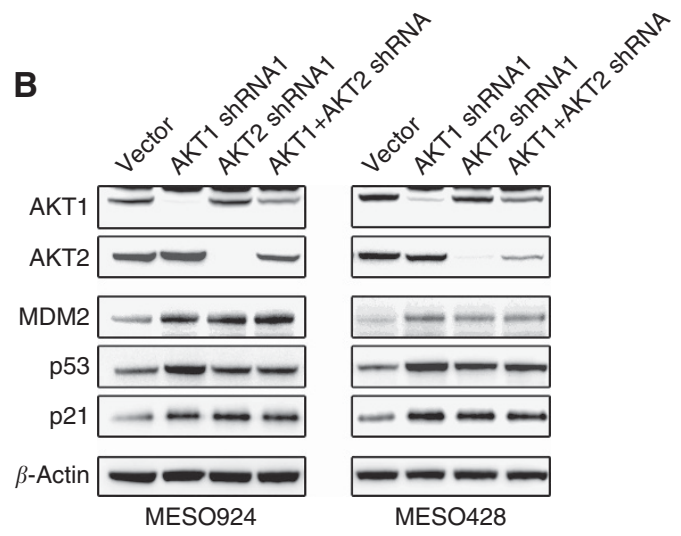

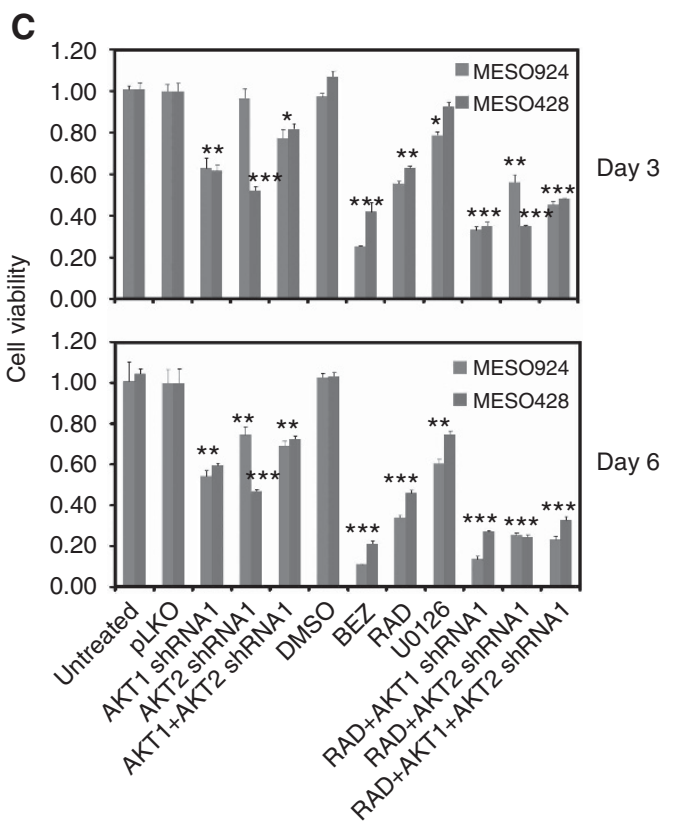

Figure 5. Single or combination AKT1/2 shRNAs and signalling intermediate inhibitor treatments in mesothelioma. (A) Imunoblotting evaluations of the effects of AKT inhibition on MDM2 activity and p53 and p21 expression in mesothelioma cell lines (MESO924 and MESO428) after treatment with GDC0941 for $72 \mathrm{~h}$. $\beta$-Actin stain is a loading control. (B) Immunoblotting evaluations of AKT1/2 knockdown, inhibition of MDM2p53-p21 axis in mesothelioma cell lines (MESO924 and MESO428) at 10 days after infection with AKT1/2 shRNA alone and in combination. $\beta$-Actin stain is a loading control. (C) Cell viability, in mesothelioma cell lines MESO924 and MESO428, was evaluated by the CellTiter-Glo luminescence assay after 3 and 6 days treatment with PI3K/mTOR (50 nM BEZ235), mTOR (20 nM RAD), MEK (10 $\mu$ M U0126) inhibitors, or AKT1/2 shRNA (AKT1/2 shRNA stable expression), alone and together. The data were normalised to the DMSO and empty vector control, and represent the mean values $( \pm$ s.d.) of quadruplicate cultures from two independent experiments. Statistically significant difference between untreated control and treatments is presented as ${ }^{\star} P<0.05,{ }^{\star *} P<0.01,{ }^{\star *} * P<0.001$.

inhibition of EGFR, MET, and AXL resulted in a 55-60\% decrease in cell viability, which was comparable to the responses obtained with dual $\mathrm{PI} 3 \mathrm{~K} / \mathrm{mTOR}$ inhibition by BEZ235 (Figure 3B). Therefore, these data underscore that simultaneous activation of multiple RTKs, including EGFR, MET, and AXL, contributes to mesothelioma cell proliferation and survival.

$\mathrm{PI} 3 \mathrm{~K} / \mathrm{AKT}$ regulation of tumorigenesis is attributable in part to mTOR (Majumder et al, 2004; Wendelet al, 2004). Unexpectedly, AKT1, AKT2, and AKT3 knockdown by shRNAs, whether singly or in combination, enhanced mTOR activation (Supplementary Figures 4 and 5), and although the mechanism is unclear, these data provide an additional rationale for dual targeting of AKT and mTOR in mesothelioma. These concepts are particularly compelling as PI3K and mTOR activation is associated with decreased survival in mesothelioma patients (Varghese et al, 2011). The in vitro evidence, here, demonstrates additive effects of
AKT1/AKT2 shRNA knockdown and RAD001 mTOR-inhibition in mesothelioma (Figures $4 \mathrm{~A}$ and $5 \mathrm{C}$ ).

We also show that loss of AKT-mediated MDM2 phosphorylation and activation resulted in decreased MDM2-mediated p53 ubiquitination and degradation, which induced p21 expression (Figure 5A). PI3K or AKT inhibition in mesothelioma induced p53 expression, associated with upregulation of MDM2 and p21 (Figure 5B and Supplementary Figure 5). In addition, a recent study showed that the PI3K/mTOR inhibitor PF-06491502 induced expression of wild-type p53 in head and neck cancer (Herzog et al, 2013). These observations suggest that the anti-proliferative and pro-apoptotic effects of PI3K/AKT inhibition in mesothelioma result both from mTOR inhibition and reactivation of p53 transcriptional programmes. This finding is in keeping with studies showing that AKT physically associates with MDM2 and phosphorylates MDM2 at Ser166 and Ser186, leading to nuclear translocation and degradation of the tumour-suppressor p53 
(Zhou et al, 2001; Singh et al, 2013), and that activation of MDM2 by AKT in mammary epithelium delays mammary involution and accelerates mammary tumorigenesis (Cheng et al, 2010).

In summary, these studies implicate a coordinated network of RTK (EGFR, MET, and AXL) as collective regulators of PI3K/ $\mathrm{AKT} / \mathrm{mTOR}$ and $\mathrm{PI} 3 \mathrm{~K} / \mathrm{AKT} / \mathrm{p} 53$ in mesothelioma, thereby regulating tumorigenesis. We provide evidence that a multipoint targeted attack on these pathways, involving concomitant inhibition of PI3K, AKT, and mTOR, might serve best to disrupt the oncogenic signalling pathways.

\section{ACKNOWLEDGEMENTS}

This research was supported by the grant from the Science and Technology Bureau of Jiaxing, Zhejiang (2012AY1039), Zhejiang leading team of Science and Technology innovation (Team No. 2010R50019), Qianjiang Talents Project of Zhejiang (2012R10079), the Major Science and Technology Special Project of Zhejiang Province (2012C03007-4), and the Zhejiang Open Foundation of the Most Important Subjects, China. This research was also supported by the Fletcher Laboratory Sundry Fund and by funding from the International Mesothelioma Program at Brigham and Women's Hospital, USA. We thank Dr Adrián Mariño-Enríquez for proof-reading and critical comments.

\section{CONFLICT OF INTEREST}

The authors declare no conflict of interest.

\section{REFERENCES}

Altomare DA, You H, Xiao GH, Ramos-Nino ME, Skele KL, De RA, Jhanwar SC, Mossman BT, Kane AB, Testa JR (2005) Human and mouse mesotheliomas exhibit elevated AKT/PKB activity, which can be targeted pharmacologically to inhibit tumor cell growth. Oncogene 24: 6080-6089.

Brevet M, Shimizu S, Bott MJ, Shukla N, Zhou Q, Olshen AB, Rusch V, Ladanyi M (2011) Coactivation of receptor tyrosine kinases in malignant mesothelioma as a rationale for combination targeted therapy. $J$ Thorac Oncol 6: 864-874.

Carbone M, Yang H (2012) Molecular pathways: targeting mechanisms of asbestos and erionite carcinogenesis in mesothelioma. Clin Cancer Res 18: 598-604.

Carracedo A, Ma L, Teruya-Feldstein J, Rojo F, Salmena L, Alimonti A, Egia A, Sasaki AT, Thomas G, Kozma SC, Papa A, Nardella C, Cantley LC, Baselga J, Pandolfi PP (2008) Inhibition of mTORC1 leads to MAPK pathway activation through a PI3K-dependent feedback loop in human cancer. J Clin Invest 118: 3065-3074.

Cedres S, Montero MA, Martinez P, Martinez A, Rodriguez-Freixinos V, Torrejon D, Gabaldon A, Salcedo M, Ramon YC, Felip E (2012) Exploratory analysis of activation of PTEN-PI3K pathway and downstream proteins in malignant pleural mesothelioma (MPM). Lung Cancer 77: 192-198.

Cheng X, Xia W, Yang JY, Hsu JL, Lang JY, Chou CK, Du Y, Sun HL, Wyszomierski SL, Mills GB, Muller WJ, Yu D, Hung MC (2010) Activation of murine double minute 2 by Akt in mammary epithelium delays mammary involution and accelerates mammary tumorigenesis. Cancer Res 70: 7684-7689.

Craighead JE (1987) Current pathogenetic concepts of diffuse malignant mesothelioma. Hum Pathol 18: 544-557.

Cole Jr GW, Alleva AM, Zuo JT, Sehgal SS, Yeow WS, Schrump DS, Nguyen DM (2006) Suppression of pro-metastasis phenotypes expression in malignant pleural mesothelioma by the PI3K inhibitor LY294002 or the MEK inhibitor UO126. Anticancer Res 26: 809-821.

Demetri GD, Zenzie BW, Rheinwald JG, Griffin JD (1989) Expression of colony-stimulating factor genes by normal human mesothelial cells and human malignant mesothelioma cells lines in vitro. Blood 74: 940-946.
Fischer B, Frei C, Moura U, Stahel R, Felley-Bosco E (2012) Inhibition of phosphoinositide-3 kinase pathway down regulates ABCG2 function and sensitizes malignant pleural mesothelioma to chemotherapy. Lung Cancer 78: $23-29$.

Gordon GJ, Rockwell GN, Jensen RV, Rheinwald JG, Glickman JN, Aronson JP, Pottorf BJ, Nitz MD, Richards WG, Sugarbaker DJ, Bueno R (2005) Identification of novel candidate oncogenes and tumor suppressors in malignant pleural mesothelioma using large-scale transcriptional profiling. Am J Pathol 166: 1827-1840.

Govindan R, Kratzke RA, Herndon JE, Niehans GA, Vollmer R, Watson D, Green MR, Kindler HL (2005) Gefitinib in patients with malignant mesothelioma: a phase II study by the Cancer and Leukemia Group B. Clin Cancer Res 11: 2300-2304.

Harvey P, Clark IM, Jaurand MC, Warn RM, Edwards DR (2000) Hepatocyte growth factor/scatter factor enhances the invasion of mesothelioma cell lines and the expression of matrix metalloproteinases. Br J Cancer 83: $1147-1153$.

Herzog A, Bian Y, Vander Broek R, Hall B, Coupar J, Cheng H, Sowers AL, Cook JD, Mitchell JB, Chen Z, Kulkarni AB, Van Waes C (2013) PI3K/ mTOR inhibitor PF-04691502 antitumor activity is enhanced with induction of wild-type TP53 in human xenograft and murine knockout models of head and neck cancer. Clin Cancer Res 19: 3808-3819.

Jacobson BA, De A, Kratzke MG, Patel MR, Jay-Dixon J, Whitson BA, Sadiq AA, Bitterman PB, Polunovsky VA, Kratzke RA (2009) Activated $4 \mathrm{E}-\mathrm{BP} 1$ represses tumourigenesis and IGF-I-mediated activation of the eIF4F complex in mesothelioma. Br J Cancer 101: 424-431.

Jagadeeswaran R, Ma PC, Seiwert TY, Jagadeeswaran S, Zumba O, Nallasura V, Ahmed S, Filiberti R, Paganuzzi M, Puntoni R, Kratzke RA, Gordon GJ, Sugarbaker DJ, Bueno R, Janamanchi V, Bindokas VP, Kindler HL, Salgia R (2006) Functional analysis of c-Met/hepatocyte growth factor pathway in malignant pleural mesothelioma. Cancer Res 66: 352-361.

Janne PA, Taffaro ML, Salgia R, Johnson BE (2002) Inhibition of epidermal growth factor receptor signaling in malignant pleural mesothelioma. Cancer Res 62: 5242-5247.

Kawaguchi K, Murakami H, Taniguchi T, Fujii M, Kawata S, Fukui T, Kondo Y, Osada H, Usami N, Yokoi K, Ueda Y, Yatabe Y, Ito M, Horio Y, Hida T, Sekido Y (2009) Combined inhibition of MET and EGFR suppresses proliferation of malignant mesothelioma cells. Carcinogenesis 30: 1097-1105.

Klominek J, Baskin B, Liu Z, Hauzenberger D (1998) Hepatocyte growth factor/scatter factor stimulates chemotaxis and growth of malignant mesothelioma cells through c-met receptor. Int J Cancer 76: 240-249.

Majumder PK, Febbo PG, Bikoff R, Berger R, Xue Q, McMahon LM, Manola J, Brugarolas J, McDonnell TJ, Golub TR, Loda M, Lane HA, Sellers WR (2004) mTOR inhibition reverses Akt-dependent prostate intraepithelial neoplasia through regulation of apoptotic and HIF-1-dependent pathways. Nat Med 10: 594-601.

Mathy A, Baas P, Dalesio O, van ZN (2005) Limited efficacy of imatinib mesylate in malignant mesothelioma: a phase II trial. Lung Cancer 50: 83-86.

Menges CW, Chen Y, Mossman BT, Chernoff J, Yeung AT, Testa JR (2010) A phosphotyrosine proteomic screen identifies multiple tyrosine kinase signaling pathways aberrantly activated in malignant mesothelioma. Genes Cancer 1: 493-505.

Menges CW, Sementino E, Talarchek J, Xu J, Chernoff J, Peterson JR, Testa JR (2012) Group I p21-activated kinases (PAKs) promote tumor cell proliferation and survival through the AKT1 and Raf-MAPK pathways. Mol Cancer Res 10: 1178-1188.

Miyoshi S, Hamada H, Hamaguchi N, Kato A, Katayama H, Irifune K, Ito R, Miyazaki T, Okura T, Higaki J (2012) Antitumor activity of MEK and PI3K inhibitors against malignant pleural mesothelioma cells in vitro and in vivo. Int J Oncol 41: 449-456.

Mukohara T, Civiello G, Davis IJ, Taffaro ML, Christensen J, Fisher DE, Johnson BE, Janne PA (2005) Inhibition of the met receptor in mesothelioma. Clin Cancer Res 11: 8122-8130.

Okamoto J, Mikami I, Tominaga Y, Kuchenbecker KM, Lin YC, Bravo DT, Clement G, Yagui-Beltran A, Ray MR, Koizumi K, He B, Jablons DM (2008) Inhibition of Hsp90 leads to cell cycle arrest and apoptosis in human malignant pleural mesothelioma. J Thorac Oncol 3: 1089-1095.

Ou WB, Corson JM, Flynn DL, Lu WP, Wise SC, Bueno R, Sugarbaker DJ, Fletcher JA (2011a) AXL regulates mesothelioma proliferation and invasiveness. Oncogene 30: 1643-1652.

Ou WB, Hubert C, Corson JM, Bueno R, Flynn DL, Sugarbaker DJ, Fletcher JA (2011b) Targeted inhibition of multiple receptor tyrosine kinases in mesothelioma. Neoplasia 13: 12-22. 
Pache JC, Janssen YM, Walsh ES, Quinlan TR, Zanella CL, Low RB, Taatjes DJ, Mossman BT (1998) Increased epidermal growth factor-receptor protein in a human mesothelial cell line in response to long asbestos fibers. Am J Pathol 152: 333-340.

Patel MR, Jacobson BA, De A, Frizelle SP, Janne P, Thumma SC, Whitson BA, Farassati F, Kratzke RA (2007) Ras pathway activation in malignant mesothelioma. J Thorac Oncol 2: 789-795.

Perrone F, Jocolle G, Pennati M, Deraco M, Baratti D, Brich S, Orsenigo M, Tarantino E, De MC, Bertan C, Cabras A, Bertulli R, Pierotti MA, Zaffaroni N, Pilotti S (2010) Receptor tyrosine kinase and downstream signalling analysis in diffuse malignant peritoneal mesothelioma. Eur J Cancer 46: 2837-2848.

Pinato DJ, Mauri FA, Lloyd T, Vaira V, Casadio C, Boldorini RL, Sharma R (2013) The expression of Axl receptor tyrosine kinase influences the tumour phenotype and clinical outcome of patients with malignant pleural mesothelioma. Br J Cancer 108: 621-628.

Pinton G, Manente AG, Angeli G, Mutti L, Moro L (2012) Perifosine as a potential novel anti-cancer agent inhibits EGFR/MET-AKT axis in malignant pleural mesothelioma. PLoS One 7: e36856.

Rodrik-Outmezguine VS, Chandarlapaty S, Pagano NC, Poulikakos PI, Scaltriti M, Moskatel E, Baselga J, Guichard S, Rosen N (2011) mTOR kinase inhibition causes feedback-dependent biphasic regulation of AKT signaling. Cancer Discov 1: 248-259.

Rubin BP, Singer S, Tsao C, Duensing A, Lux ML, Ruiz R, Hibbard MK, Chen CJ, Xiao S, Tuveson DA, Demetri GD, Fletcher CD, Fletcher JA (2001) KIT activation is a ubiquitous feature of gastrointestinal stromal tumors. Cancer Res 61: 8118-8121.

Sahin AA, Coplu L, Selcuk ZT, Eryilmaz M, Emri S, Akhan O, Baris YI (1993) Malignant pleural mesothelioma caused by environmental exposure to asbestos or erionite in rural Turkey: CT findings in 84 patients. AJR Am J Roentgenol 161: 533-537.

Selcuk ZT, Coplu L, Emri S, Kalyoncu AF, Sahin AA, Baris YI (1992) Malignant pleural mesothelioma due to environmental mineral fiber exposure in Turkey. Analysis of 135 cases. Chest 102: 790-796.

Shukla A, Hillegass JM, MacPherson MB, Beuschel SL, Vacek PM, Butnor KJ, Pass HI, Carbone M, Testa JR, Heintz NH, Mossman BT (2011) ERK2 is essential for the growth of human epithelioid malignant mesotheliomas. Int J Cancer 129: 1075-1086.

Singh S, Ramamoorthy M, Vaughan C, Yeudall WA, Deb S, Palit DS (2013) Human oncoprotein MDM2 activates the Akt signaling pathway through an interaction with the repressor element-1 silencing transcription factor conferring a survival advantage to cancer cells. Cell Death Differ 20: 558-566.

Skehan P, Storeng R, Scudiero D, Monks A, McMahon J, Vistica D, Warren JT, Bokesch H, Kenney S, Boyd MR (1990) New colorimetric cytotoxicity assay for anticancer-drug screening.J. Natl Cancer Inst 82: 1107-1112.

Suzuki Y, Murakami H, Kawaguchi K, Tanigushi T, Fujii M, Shinjo K, Kondo Y, Osada H, Shimokata K, Horio Y, Hasegawa Y, Hida T, Sekido Y (2009) Activation of the PI3K-AKT pathway in human malignant mesothelioma cells. Mol Med Report 2: 181-188.

Tolnay E, Kuhnen C, Wiethege T, Konig JE, Voss B, Muller KM (1998) Hepatocyte growth factor/scatter factor and its receptor c-Met are overexpressed and associated with an increased microvessel density in malignant pleural mesothelioma. J Cancer Res Clin Oncol 124: 291-296.

Varghese S, Chen Z, Bartlett DL, Pingpank JF, Libutti SK, Steinberg SM, Wunderlich J, Alexander Jr. HR (2011) Activation of the phosphoinositide-3-kinase and mammalian target of rapamycin signaling pathways are associated with shortened survival in patients with malignant peritoneal mesothelioma. Cancer 117: 361-371.

Wendel HG, de SE, Fridman JS, Malina A, Ray S, Kogan S, Cordon-Cardo C, Pelletier J, Lowe SW (2004) Survival signalling by Akt and eIF4E in oncogenesis and cancer therapy. Nature 428: 332-337.

Xia G, Kumar SR, Masood R, Koss M, Templeman C, Quinn D, Zhu S, Reddy R, Krasnoperov V, Gill PS (2005) Up-regulation of EphB4 in mesothelioma and its biological significance. Clin Cancer Res 11: $4305-4315$.

Zanella CL, Posada J, Tritton TR, Mossman BT (1996) Asbestos causes stimulation of the extracellular signal-regulated kinase 1 mitogen-activated protein kinase cascade after phosphorylation of the epidermal growth factor receptor. Cancer Res 56: 5334-5338.

Zhou BP, Liao Y, Xia W, Zou Y, Spohn B, Hung MC (2001) HER-2/neu induces p53 ubiquitination via Akt-mediated MDM2 phosphorylation. Nat Cell Biol 3: 973-982.

This work is published under the standard license to publish agreement. After 12 months the work will become freely available and the license terms will switch to a Creative Commons AttributionNonCommercial-Share Alike 3.0 Unported License.

Supplementary Information accompanies this paper on British Journal of Cancer website (http://www.nature.com/bjc) 